\title{
A Comparison between Premortem and Postmortem Diagnosis in Trauma Cases
}

\author{
Dua Sumeyra Demirkiran1, Ibrahim Ortanca1, Mustafa Sahan2, Adnan Celikel1, \\ Muhammet Mustafa Arslan ${ }^{*}$ \\ ${ }^{1}$ Department of Forensic Medicine, Medical Faculty of Mustafa Kemal University, Serinyol, Hatay, Turkey \\ ${ }^{2}$ Department of Emergency Medicine, Medical Faculty of Mustafa Kemal University, Serinyol, Hatay, Turkey \\ Email: ${ }^{*}$ mmustafaarslan@yahoo.com
}

Received 9 October 2015; accepted 25 October 2015; published 28 October 2015

Copyright (C) 2015 by authors and Scientific Research Publishing Inc.

This work is licensed under the Creative Commons Attribution International License (CC BY). http://creativecommons.org/licenses/by/4.0/

(c) $\underset{\mathrm{EY}}{\mathrm{EY}}$ Open Access

\section{Abstract}

This study evaluated the comparison of premortem and postmortem diagnoses of trauma cases that died during treatment and then autopsied. We had analyzed the autopsy reports of forensic deaths retrospectively which occurred between 2013 and 2014. The cases that died because of trauma and which had complete medical reports were included the study. Totally 626 cases were autopsied and 307 cases records were examined from them. The mean age was found to be 28.11. According the treatment period, it was detected that $116(37.8 \%)$ cases died within the first 24 hours. Discrepancies between premortem and postmortem diagnoses were determined in $20.6 \%$ of cases. $5.9 \%$ had a main diagnostic discrepancy and $14.7 \%$ were of second lethal diagnoses. The discrepancies were observed mostly in the multiple injury cases. In our study, diagnostic discrepancy rate was higher in multiple injury cases especially who died by explosion. When clinicians focus on the treatment according to their main diagnosis, they overlook the fatal injuries in other parts of the body. This study shows that autopsy is the most reliable method for the confirmation of the clinical diagnosis in trauma patients. Therefore, particularly surgery physicians should compare the results of the autopsy diagnoses to their own diagnosis.

\section{Keywords}

\section{Clinical Diagnosis, Autopsies, Trauma}

\section{Introduction}

It has been reported that autopsy is the most accurate method used to confirm causes of death, clinical diagnoses

\footnotetext{
${ }^{*}$ Corresponding author.
}

How to cite this paper: Demirkiran, D.S., Ortanca, I., Sahan, M., Celikel, A. and Arslan, M.M. (2015) A Comparison between Premortem and Postmortem Diagnosis in Trauma Cases. Forensic Medicine and Anatomy Research, 3, 89-94. 
and results of diagnostic tests [1]. In a study, using a questionnaire, most of the participants noted that autopsy played an important role in practice and education [2]. It has a great value especially in cases of medical malpractice. In fact, it helps reveal complications or malpractices which remain undetected [3].

There has been a gradual decrease in the number of autopsies in recent decades. It has been reported to be due to the availability of modern diagnostic methods and presentation of objective findings. However, it has been stated that advances in medical technologies do not bring a considerable reduction in the incidence of misdiagnoses [4].

The incidence of misdiagnoses has been found to be $10 \%$ and similar across studies performed at different times [5]. Several other studies have revealed a higher incidence of misdiagnoses. Cameron et al. found discrepancies in diagnoses in $15 \%$ of the cases in one study [6] and in another study they found discrepancies in major diagnoses in $39 \%$ of the cases and other diagnoses contributing to death in $66 \%$ of the cases [7]. Ermenc compared clinical diagnoses and diagnoses made at autopsies in 911 cases and found that both diagnoses were completely consistent in $49.30 \%$ of the cases and were partly consistent in $20.68 \%$ of the cases, but were not consistent in $6.87 \%$ of the cases [4]. In another study, the cause of death was found to be misdiagnosed in at least one third of the cases and conditions not suspected before death that turned out to be diagnosed at autopsy in $50 \%$ of the cases [1].

There have been two studies comparing premortem and postmortem diagnoses in Turkey. Both studies were performed on patients claimed to die after surgery due to malpractice. Premortem and postmortem diagnoses were found to have discrepancies in $18 \%$ of the cases in one study and in $49.1 \%$ of the cases in the other [8] [9].

Data obtained before and after death from the cases of trauma are invaluable to determine the most appropriate approach to these patients. The aim of the present study is to compare premortem and postmortem diagnoses of patients died after treatment and undergone autopsy and to make recommendations about approaches to the cases of trauma.

\section{Material and Methods}

Autopsy reports of forensic cases which were referred to the attorney general in Hatay between January 2013 and September 2014 were retrospectively reviewed. Cases found to be dead, not having sufficient data, not investigated or not having a diagnosis before death were excluded. Cases exposed to the process of examinations, routine radiological investigations and having at least one diagnosis before death were included into the study. Findings about premortem period were collected from patient records or reports. Considering that data about nosocomial infections/complications are missing or insufficient, only diagnoses of trauma were evaluated. Data about age, gender, trauma and treatment until death were obtained from hospital patient records. Postmortem findings, information and documented cause of death are obtained from the death records and autopsy reports of same people. Premortem and postmortem diagnoses of death were categorized as completely consistent, inconsistent and partly consistent, that, have another lethal lesion apart from the primary diagnosis. Time from trauma to death was classified into "in 24 hours" and "in more than 24 hours". Causes of death were categorized into gunshot wounds, explosions, traffic accidents, falls and others including injuries with sharp objects, burns and being under wreckage. Obtained data were analyzed with Statistical Package for the Social Sciences (SPSS) 15.0. Descriptive analyses for frequency and percentages chi-square test for variables are used.

\section{Results}

A total of 626 cases underwent conventional autopsy between January 2013 and September 2014 and a total of 307 cases fulfilling the inclusion criteria mentioned in Material and Methods were included into the study. Of 307 cases, 277 (90.2\%) were male and 30 (9.8\%) were female. The youngest case was 7 months old and the oldest one was 89 years old and the mean age of the cases was 28.11 years. The mean age was 27.3 years in the cases without discrepancies between their premortem and postmortem diagnosis and it was41.8 years in the cases with discrepancies between their diagnosis (Table 1). Premortem and postmortem diagnosis were consistent in $79.5 \%$ of the cases (Figure 1).

Of 307 cases, 116 (37.8\%) died within 24 hours of their treatment, 191 (62.2\%) died 24 hours after their treatment. Among the ones who died in 24 hours; 75\% (n: 87) of the cases are without discrepancy, 6.9\% (n: 8) are with discrepancy, $18 \%$ (n: 21) are with secondary diagnosis. Among the ones who died after 24 hours; 82.2\% (n: 157) of the cases are without discrepancy, 5.2\% (n: 10) are with discrepancy, 12.6\% (n: 24) are with secondary 


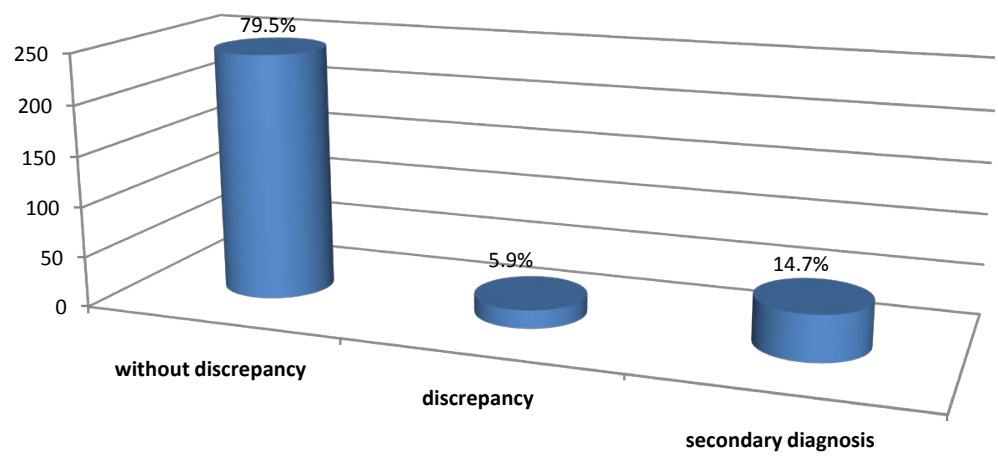

Figure 1. Correspondence of premortem-postmortem diagnosis.

Table 1. Mean ages according to premortem-postmortem diagnosis.

\begin{tabular}{cccc}
\hline & Mean age & Minimum & Maximum \\
\hline Without discrepancy & $27,290$ (n: 244$)$ & 7 months & 89 years \\
Discrepancy & $41,889(\mathrm{n}: 18)$ & 1 year & 86 years \\
Secondary diagnosis & $27,222(\mathrm{n}: 45)$ & 2 years & 70 years \\
Total & $28,136$ (n: 307$)$ & 7 months & 89 years \\
\hline
\end{tabular}

diagnosis. Among the cases without discrepancy 35.7\% (n: 87) died in first 24 hours, 64.3\% (n: 157) died after 24 hours. Among the cases with discrepancy 44.4\% (n: 8) died in first 24 hours, 55.6\% (n: 10) died after 24 hours. Among the cases with secondary diagnosis 45.7\% (n: 21) died in first 24 hours, 53.3\% (n: 24) died after 24 hours (Table 2).

The cause of death was canister shots in 172 cases (56.0\%), gunshot wounds in 80 cases (26.1\%), traffic accidents in 20 cases (6.5\%) and falls from a high place in 25 cases (8.1\%) and others in 10 cases (3.3\%). The results were not statistically significant. When premortem and postmortem diagnoses were compared (Table 3 ), a secondary lethal lesion was most frequently found to be in deaths due to explosions. In addition, out of 18 cases with discrepancies between premortem and postmortem diagnoses, 12 were found to die due to explosions or falls from a high place. Of these, 14casesdied within the first 24 hours and 8 cases were identified the major vascular injuries.

\section{Discussion}

It has been reported that age, gender, quality of hospitals and types of diseases may play a role in discrepancies between premortem and postmortem diagnoses, but genders do not significantly differ in terms of changes in their major diagnoses [10]. In the present study, $90.2 \%$ of the cases were male. It may be because only patients having traumas were included into the study. In fact, most of the cases autopsied were the ones died from traumas in wars, which might have caused preponderance of the male gender in the sample.

Yayci et al. found that discrepancies between premortem and postmortem diagnoses most frequently appeared in the cases aged 16 - 45 years [8]. Goldman et al. reported no discrepancies in cases younger than 40 years and those older than 60 years [5]. In another study, cases aged 1 - 40 years were found to have changes in their major diagnoses [9]. Cameron reported that changes in diagnoses most frequently appeared in elderly patients [7]. In the present study, the mean age of the cases in which changes in major diagnoses occurred was 41.8 years. Although the cases included in this study had traumas, the age group with changes in their major diagnoses was consistent with that reported in the literature.

It has been shown that the rate of cases with discrepancies between premortem and postmortem diagnoses varies from $15 \%$ to $63 \%$ [7] [11]. Although it is claimed that advances in diagnostic procedures reduce needs for autopsies, comparative studies underline the fact that major diagnoses can still change at autopsy. In one study directed towards determining whether rates of misdiagnoses decreased despite advanced diagnostic methods, a retrospective analysis of the cases encountered in one hospital during four different periods of time at 10 years 
Table 2. Treatment time according to premortem-postmortem diagnosis.

\begin{tabular}{|c|c|c|c|c|}
\hline \multicolumn{2}{|c|}{ Diagnosis } & \multicolumn{2}{|c|}{ Treatment time } & \multirow[t]{2}{*}{ Total } \\
\hline & & 0 - 24h & $24 \mathrm{~h}$ and more & \\
\hline Without discrepancy & Cases number & $87(35.7 \%)$ & 157 (64.3\%) & $244(100.0 \%)$ \\
\hline Discrepancy & Cases number & 8 (44.4\%) & $10(55.6 \%)$ & $18(100.0 \%)$ \\
\hline Secondary diagnosis & Cases number & $21(46.7 \%)$ & $24(53.3 \%)$ & $45(100.0 \%)$ \\
\hline Total & Cases number & 116 & 191 & 307 \\
\hline
\end{tabular}

Table 3. Premortem-postmortem diagnosis according to ethology of trauma.

\begin{tabular}{ccccccc}
\hline \multirow{2}{*}{ Diagnosis } & \multicolumn{5}{c}{ Ethology of trauma (\%) } & Total (\%) \\
\cline { 2 - 6 } & Explosion & Gunshot & Traffic accident & Falls from high place & Others & \\
\hline Without discrepancy & $134(54.9 \%)$ & $67(27.5 \%)$ & $18(7.4 \%)$ & $18(7.4 \%)$ & $7(2.9 \%)$ & $244(100.0 \%)$ \\
Discrepancy & $6(33.3 \%)$ & $3(16.7 \%)$ & $1(5.6 \%)$ & $6(33.3 \%)$ & $2(11.1 \%)$ & $18(100.0 \%)$ \\
Secondary diagnosis & $32(71.1 \%)$ & $10(22.2 \%)$ & $1(2.2 \%)$ & $1(2.2 \%)$ & $1(2.2 \%)$ & $45(100.0 \%)$ \\
\multicolumn{1}{c}{ Total } & $172(56.0 \%)$ & $80(26.1 \%)$ & $20(6.5 \%)$ & $25(8.1 \%)$ & $10(3.3 \%)$ & $307(100.0 \%)$ \\
\hline
\end{tabular}

intervals showed changes in diagnoses at autopsy in $10 \%$ of the cases [12]. In a study by Coradazzi et al., $50 \%$ of the cases had a secondary diagnosis clinically not suspected and the rate of discrepancies between clinical diagnoses and diagnoses at autopsies was higher in the cases with a secondary diagnosis [13]. In the current study, the rate of discrepancies in major diagnoses was 5.9\% (Figure 1), which was lower than that reported in the literature. It can be explained by the fact that a multidisciplinary approach is adopted in cases of traumas. In addition, $14.7 \%$ of the cases had a trauma-related pathological condition not clinically diagnosed but contributing to death. This indicates that clinicians designing follow-up and treatment for a major diagnosis may overlook a secondary condition which can be fatal.

While some studies reveal that a prolonged hospital stay increases rates of misdiagnoses, others propose the opposite. The former group of studies shows that infections are most frequently overlooked in $25 \%$ of the misdiagnosed cases. Therefore, they argue that cases with a primary diagnosis dying within 48 hours of their admission to intensive care units are less likely to be misdiagnosed since they die before contracting an infection [14] [15]. The latter group of the studies indicate that major diagnoses have changed in $67 \%$ of the cases dying within the first 24 hours and attribute these changes to the fact that these deaths occur before medical interventions are performed and necessary consultations are performed [9]. In the current study, at autopsies, there was a change in major diagnoses of $6.9 \%$ of the cases dying within 24 hours of their admission and $18.1 \%$ of the cases had a secondary diagnosis the clinicians could not predict. Premortem and postmortem diagnoses were consistent in $82.2 \%$ of the cases which stayed in hospital for more than 24 hours (Table 2). It was thought that the high discrepancies in dying within the first 24 hours is due to the lack of time to request the consultation and diagnostic tests and insufficient of history. However, if cases of nosocomial infections had been included in the sample, the rate of changes in diagnoses of cases surviving for more than 24 hours could have increased.

Studies comparing premortem and postmortem diagnoses have been performed on cases of natural medical conditions other than traumas. In the present study, when the relation between etiologies of traumas and discrepancies in diagnoses was examined, it turned out that 33.3\% of 18 cases with diagnostic discrepancies and $71.1 \%$ of 45 cases with a secondary diagnosis died due to explosions. Since canister pieces cause injuries in many parts of the body in cases exposed to explosions, health professionals might have overlooked conditions posing risk of death while attempting to treat major conditions. Likewise, the rate of discrepancies was higher in cases of falls from a high place. These findings indicate that changes in major and secondary diagnoses were more frequent in cases of multiple traumas. It has been suggested in the literature that health staff should act as a trauma team in scenes where a high number of deaths occur due to traumas [16]. Rates of preventable deaths are lower in areas where there are trauma centers because these centers establish an integration of emergency health care and care 
offered in these centers and thus reduce death rates in cases of traumas [17]. A multidisciplinary approach and an experienced health care team will decrease misdiagnoses.

It has been reported that advances in medical technologies, especially radiological methods do not reduce rates of misdiagnoses [12]. In the light of the evidence from the literature and the present study, it is striking that discrepancies between premortem and postmortem diagnoses reported from different countries are similar despite social, cultural, economic and technological differences. All imaging techniques and treatments expected to be offered routinely are free of charge. Despite this, rates of discrepancies are high, which emphasizes the role of taking history, performing examinations and having a multidisciplinary approach in making accurate diagnoses. It should be kept in mind that patients with multiple traumas can have lethal lesions apart from a major medical condition.

The lack of minor lesion records in patients' medical reports and inability to evaluate nosocomial infections and the complications due to injuries are important limitations of our study. Therefore, a prospective study evaluating those issues would be more helpful to support mentioned issues.

\section{Conclusion}

To conclude, the rates of misdiagnoses were not low in spite of advances in imaging techniques. The rates of discrepancies between premortem and postmortem diagnoses were higher especially in cases of deaths due to explosions. It may be that unlike other studies reported so far, this study includes only trauma cases. Autopsy is the most reliable method to confirm clinical diagnoses in trauma cases. It helps to reveal unnecessary or risky medical interventions and thus makes one its greatest contributions to medical advances. It is also indispensable in that it helps to evaluate the reliability of medical education and treatment given. Therefore, physicians specializing in surgical units should be able to evaluate the results of autopsy cases.

\section{References}

[1] Roulson, J., Benbow, E.W. and Hasleton, P.S. (2005) Discrepancies between Clinical and Autopsy Diagnosis and the Value of Post Mortem Histology; a Meta-Analysis and Review. Histopathology, 47, 551-559. http://dx.doi.org/10.1111/j.1365-2559.2005.02243.x

[2] McGoogan, E. and Cameron, H.M. (1978) Clinical Attitudes to the Autopsy. Scottish Medical Journal, 23, $19-22$.

[3] Juvin, P., Teissière, F., Brion, F., Desmonts, J.M. and Durigon, M. (2000) Postoperative Death and Malpractice Suits: Is Autopsy Useful? Anesthesia \& Analgesia, 91, 344-346.

[4] Ermenc, B. (2000) Comparison of the Clinical and Post Mortem Diagnoses of the Causes of Death. Forensic Science International, 114, 117-119. http://dx.doi.org/10.1016/S0379-0738(00)00329-7

[5] Goldman, L., Sayson, R., Robbins, S., Cohn, L.H., Bettmann, M. and Weisberg, M. (1983) The Value of the Autopsy in Three Different Eras. The New England Journal of Medicine, 308, 1000-1005. http://dx.doi.org/10.1056/NEJM198304283081704

[6] Cameron, H.M. (1981) The Autopsy as a Clinical Investigation. Journal of the Royal Society of Medicine, 74, 713-715.

[7] Cameron, H.M., McGoogan, E. and Watson, H. (1980) Necropsy: A Yardstick for Clinical Diagnosis. British Medical Journal, 281, 985-988. http://dx.doi.org/10.1136/bmj.281.6246.985

[8] Yaycı, N., Üzün, I., Arslan, M.M. and Iris, M. (2004) Postoperatif Ölümle Sonuçlanmışve Tıbbi Uygulama Hatası İddiası Bulunan Olgularda Otopsinin Değeri. Türkiye Klinikleri Adli Tip Dergisi, 1, 57-61.

[9] Pakis, I., Polat, O., Yayci, N. and Karapirli, M. (2010) Comparison of the Clinical Diagnosis and Subsequent Autopsy Findings in Medical Malpractice. American Journal of Forensic Medicine \& Pathology, 31, 218-221. http://dx.doi.org/10.1097/PAF.0b013e3181e040d4

[10] Battle, R.M., Pathak, D. and Humble, C.G. (1987) Factors Influencing Discrepancies between Premortem and Postmortem Diagnosis. JAMA, 258, 339-344. http://dx.doi.org/10.1001/jama.1987.03400030055031

[11] Mosquera, D.A. and Goldman, M.D. (1993) Surgical Audit without Autopsy: Tales of the Unexpected. Ann R CollSurg Engl, 75, 115-117.

[12] Kirch, W. and Schafii, C. (1996) Misdiagnosis at a University Hospital in 4 Medical Eras. Medicine (Baltimore), 75, 29-40. http://dx.doi.org/10.1097/00005792-199601000-00004

[13] Coradazzi, A.L., Morganti, A.L. and Montenegro, M.R. (2003) Discrepancies between Clinical Diagnoses and Autopsy Findings. Brazilian Journal of Medical and Biological Research, 36, 385-391.

http://dx.doi.org/10.1590/S0100-879X2003000300014 
[14] Stevanovic, G., Tucakovic, G., Dotlic, R.D. and Kanjuh, V. (1986) Correlation of Clinical Diagnoses and Autopsy Findings: A Retrospective Study of 2145 Consecutive Autopsies. Human Pathology, 17, 1225-1230. http://dx.doi.org/10.1016/S0046-8177(86)80564-0

[15] Tai, D.Y., El-Bilbeisi, H., Tewari, S., Mascha, E.J., Wiedemann, H.P. and Arroliga, A.C. (2001) A Study of Consecutive Autopsies in a Medical ICU. A Comparison of Clinical Cause of Death and Autopsy Diagnosis. Chest, 119, 530536. http://dx.doi.org/10.1378/chest.119.2.530

[16] Holcomb, J., Caruso, J., McMullin, N., Wade, C.E., Pearse, L., Oetjen-Gerdes, L., Champion, H.R., Lawnick, M., Farr, W., Rodriguez, S. and Butler, F. (2007) Causes of Death in US Special Operations Forces in the Global War on Terrorism: 2001-2004. U.S. Army Medical Department Journal, 24-37.

[17] Eyi, Y.E., Toygar, M., Karbeyaz, K., Kaldırım, Ü., Tuncer, S.K. and Durusu, M. (2015) Evaluation of Autopsy Reports in Terms of Preventability of Traumatic Deaths. Ulusal Travma ve Acil Cerrahi Dergisi, 2, 127-133. 